\title{
RITUAL POLLUTION AMONG INDIAN TAMILS IN MALAYSIA*: AN EXPLANATION
}

\author{
RAJAKRISHNAN A/L RAMASAMY
}

\section{Concept of Pollution}

The concept of purity and pollution is a central theme in the socio-cultural life of the Hindus. It determines not only the extent of relationship between individuals and groups but also identifies what is pure and impure. Most objects, acts, people and places have been labelled relatively pure or impure by the Hindus. Thus we find a classification that 'Sanskritic' deities are pure and 'non-Sanskritic' deities as impure, higher castes as pure and lower castes as polluting, cow's urine and faeces as pure and human urine and faeces as polluting, men purer than women and jungles purer than villages. Pollution is usually associated with death, birth, decay, human emissions, disease, unclean animals, and consumption of meat and alcohol. So also is sin arising from taking of life, from the sin of killing and eating beef and from sin in general. Such items, acts and events which assign an individual the state of purity or impurity also assign his place in the social structure. Anyone having any association with the above sources of impurity or undertaking occupations related to them are considered defiling and hence deemed a low caste. Coming into contact with an agent of pollution, directly or indirectly, was considered polluting since the transmission of pollution takes place either through touch, sight, distance and even shadow. ${ }^{1}$

In discussing the concept of purity and pollution one usually lays more emphasis on defining the state of pollution because purity is "evanescent and fleeting" while pollution is "well-defined and clinging state of being"2. Purity is the attainment of a transient elevation rather than any lasting presence of grace. Being in a state of purity is a temporary phenomenon as pollution will sooner or later overcome purity. This is mainly because one's own biological functions are regarded as the main source of pollution. Everyone in a normal state is not regarded

\footnotetext{
*The data for this article on ritual pollution practised by the Indian Tamils in Malaysia were collected when the author did research on caste consciousness among Indian Tamils in Malaysia in 1977.

${ }^{1}$ See L. Dumont., Homo Hierarchicus : the caste system and its implications (Trans. by Mark Sainsbury), (London, Weidenfeld and Nicolson, 1970), pp. 50-60; G.S. Ghurye., Caste and Race in India. (Bombay, Popular Prakashan, 1959) pp. 8-11; D.G. Mandelbaum., Society in India : Continuity and Change. Vol. I. (Berkeley, University of California Press, 1970), pp. 184-205.

2 D.G. Mandelbaum, ibid., p. 192.
} 
as pure or impure but in "a mild form of impurity" 3 and a person's condition can be changed either way by acts like urination, defecation, intercourse, eating or touching unclean objects. Such forms of pollution are less strictly observed, and if observed, the pollution is very easily removed by washing or bathing. But pollution radiated by birth, death and menstruation is believed to stay for a specified period of time depending on customs and how much one tries to wash or bathe it cannot be removed. A purification ceremony must be conducted to remove the pollution so attached.

The functional relationship of the purity-pollution concept to caste ranking is obvious, but the question of temporary pollution caused by certain acts and events in daily life cannot be explained by this functional approach. Then there are also questions like kin group pollution where members of the same caste or group are affected by variations in purity and pollution relating to birth, death and menstruation and not marriage, which is important in defining group boundaries. In outlining the mode of observance of temporary pollution among the Indians in Malaysia, with particular reference to pollution brought by such events as birth, death and menstruation, an attempt is made in this article to provide a plausible explanation to the basic question of what gives rise to or what constitutes the notion of pollution.

\section{Pollution as practised in Malaysia}

Pollution is commonly known as titttu among the Indian Tamils in Malaysia. It invariably applies to pollution caused by birth, death and menstruation. In the course of the writer's fieldwork it was found that the use of the term titțu was inappropriate in any other context except the pollution caused by the above three sources. ${ }^{4}$ Acuttam or uncleanliness which also implied pollution was used to describe the state of impurity brought about by other bodily emissions like faeces, urine or saliva and decay, touching unclean objects and other sources of pollution. Pollution arising from acuttam can be removed easily by washing or taking a bath whereas $t \bar{\imath} t \underline{t} u$ stays for a specified period of time after which a purificatory ceremony is held to remove the pollution. Titțu usually involved kinship group while acuttam is a more individualised state.

In Malaysia a number of restrictions are imposed on a girl who first menstruates. On knowing that the girl has menstruated for the first time, referred to as having

\footnotetext{
${ }^{3}$ M.N. Srinivas, Religion and Society among the Coorgs in South India. (Oxford, Clarendon Press, 1952), p. 107.

${ }^{4}$ A. Mani in his thesis entitled Changing Structure of Caste among Singapore Hindus (M.Soc.Sc. Thesis, Department of Sociology, University of Singapore, Singapore, 1976) defines tīttu as encompassing all states of pollution. However, the present writer thinks that there is a marked difference between that state of pollution which arises from birth, death and menstruation and that which arises from other sources.
} 
attained age, she is secluded in a room or a portion of the house. In earlier days a separate hut was constructed outside the house and the girl kept and fed there. After the period of isolation of nine days a special ceremony to mark the end of pollution is held, after which she could move freely and intermingle with family members. However nowadays because of schooling, the period of nine days is seldom observed. A shorter period is observed followed by a simple ceremony. Subsequent menstruation also brings along with it the stigma of pollution and the menstruating women are expected to bathe twice a day (morning and evening), not allowed to cook food, not allowed to attend marriages or other auspicious functions, do not enter other's houses, sleep away from other members in the family, do not go to temples or enter the prayer room in the home, do not light the sacred lamp, do not apply holy ash or vibhüti, do not water plants, do not play or carry small babies and do not feed household pets. ${ }^{5}$ Such restrictions are observed for a period of three days. However, in Malaysia most families are of the elementary type where the wife plays the role of mother and housekeeper. As such it becomes impossible to observe some of the restrictions like not cooking food or carrying the babies. But in matters dealing with the sacred the menstruating woman excludes herself. She is usually advised to carry an iron key or nail when leaving the house to ward off evil influences.

In the case of birth, pollution starts in the seventh month of pregnancy and a special ceremony called valaikāppu is held to protect the pregnant mother from untoward influences. She is not expected to enter temples or have sexual intercourse and is required to stay in the house between sunrise and sunset to avoid evil spirits. After delivery the mother and child are isolated for a period of sixteen days when a purification ceremony called patinar period of pollution lingers till the thirtieth day. On the thirty-first day the mother and child are taken to the temple for prayers. However, nowadays many of the restrictions could not be observed because the pregnant mother, after the seventh month of pregnancy, had to make frequent visits to the hospital for regular checkups and deliveries are in the hospital where she spends the first three days after childbirth. Being a happy occasion the notion of pollution is less strictly observed and the family members are allowed to interact freely with the mother and child.

Compared to birth and menstruation, pollution brought by death is much more severe, hence the observation in terms of period, extent and nature is strict. When a death occurs in a plantation settlement the temple is temporarily closed till

\footnotetext{
${ }^{5}$ Tamils believe that babies touched by menstruating women will be affected by some form of ill-omen called tossham which needs to be removed only through a special ceremony. They do not feed household pets as the pets will excrete fluid in the eyes while the menstruating woman is believed to suffer from stomach ache. Plants watered by such women will die.
} 
the cremation or burial is over. A purification ceremony is performed by the priest at the temple before any worship is allowed. The house where the funeral had occurred is considered polluted and no cooking is done in the house till the corpse had been removed from the house. The house, utensils and sometimes clothes are all washed before being used. Those who attend a funeral consider themselves polluted, though temporarily, and clean themselves in a number of ways according to convenience before entering the house. There are those who bathe in a river or elsewhere before coming to their houses, others enter by the backdoor and bathe immediately while some bathe outside their house before entering. In urban areas, those living in high rise homes who could not enter by the backdoor, sprinkle some water over their heads, enter the house and proceed straight to the bathroom for a bath. In all the cases the clothes are washed immediately. Whichever way is adopted to purify oneself depending on facilities and constraints, the notion of pollution still lingers in the mind of the Hindus.

On the eighth day after the funeral, a mourning ceremony called ettām tukkam is held, followed by a purification ceremony on the sixteenth day called karumāti which ends the immediate pollution. Thereafter worship is allowed in the house or temple. But the period of extended pollution is observed for a period of one year during which no auspicious functions are held or celebrated. The kin group members, both in the house and living outside, in the country and sometimes outside, when informed of the death observe the immediate period of pollution by not worshipping the divine and not consuming meat and alcohol. The extended period of pollution of one year is observed only by close and immediate relatives of the deceased. In the case of a marriage which had already been scheduled but which falls within the extended period of pollution, close as well as distant patrilineal or matrilineal kin may not observe the restriction.

What is surprising here is that almost all Hindus observe the pollution related to death, birth and menstruation as a matter of cultural or customary practice without knowing or understanding the significance or explanation behind it. When enquired why they consider themselves polluted as a result of a birth or first menstruation which are actually happy occasions, no plausible explanation was forthcoming. Likewise when death occurred why should one consider himself polluted when the dead is already disposed off? Though they could not provide an answer or explanation behind the observance of pollution, they were able to state one fact clearly, that is, during the period of pollution those associated with birth, death and menstruation, be it the first or subsequent emission, are not supposed to go near the sacred. The characteristic of being in a state of uncleanliness or inauspiciousness forbids them from approaching something sacred or divine, and that is why they do not enter temples, prayer rooms or even participate actively in marriages which is an auspicious and sacred union. Hindus, when fixing the engagement or wedding day, will avoid the period of pollution or tĩt tu $u$ as it is 
considered inauspicious. Similarly, when in communication with the sacred or going to temples or preparing for prayers in the house, one is expected not to have come into contact with sources of acuttam or consumed meat or liquor. Hindu women who usually undertake viratam or fast for some motive, avoid consuming meat during the period of fasting. Meat is generally not considered polluting as it had become an acceptable food item among the Hindus in Malaysia, but as it is believed to contradict the sacred it is avoided. ${ }^{6}$ Internal pollution is much more serious than external pollution which cannot be removed by bathing. Abstention is the only way to avoid pollution.

What is obvious from the above mode of observance of pollution is that anyone affected by pollution, be it titțu or acuttam, he is deemed unfit to communicate with the divine forces. The other restrictions have been incidental in the observation of pollution which varied according to place, time and circumstances. There are no stringent rules regarding their observance as compared to confronting the sacred. Those under the influence of tītțu will not and dare not go to temples nor enter the prayer rooms. Pollution may not be something visible but it certainly lays certain constraints on the individual or individuals. It is a kind of invisible bond which is seldom broken for fear of repercussions as they are dealing with the divine forces. ${ }^{7}$ Among the Tamils when a scorpion or snake is found in the home or a member of the house meets an accident after a female visitor, young or middle aged, had left the house the suspicion is that the visitor must have been menstruating and had not completed the period of pollution. ${ }^{8}$

The question again arises as to what exactly this titțu is and why there is the fear to confront the sacred when in the state of titțu. The simple explanation is that one is impure and unclean, but what is the cause of this impurity or uncleanliness?

\section{An explanation of pollution}

Durkheim points out that in most primitive societies there are positive and negative cults, whose purpose or function is to preserve the identity of the sacred

\footnotetext{
${ }^{6}$ In the worship of minor deities like Kāțteri, Muniyānḍi, Pēccāyi etc., meat and alcohol are important offerings. This is normal practice in 'non-Sanskritic' Hinduism and that is why 'non-Sanskritic' deities are regarded as impure. In 'Sanskritic' worship only vegetarian items are offered.

${ }^{7}$ In my observation of Hindus, they evince more fear than love of the divine forces. In the psychological dimension of worship fear of repercussion is a primal factor since Hindus generally believe that if they do not worship the supernatural or divine forces they have to face the consequences. Propitiation pleases the divine.

${ }^{8} \mathrm{~A}$ dhobi is considered polluting because of his permanent association with soiled and menstrual clothes. He is considered inauspicious and therefore when setting out on a journey or to discuss an important matter e.g., marriage, business etc, Tamils will avoid seeing a dhoby. If the dhoby is seen by accident, the person postpones his journey.
} 
and the profane spheres of life and to prevent any contact between the two. ${ }^{9}$ The positive cult preserves the sacred, while the negative cult preserves the distinctness of the sacred and the profane spheres. Both consist of prescribing rituals. The profane must not touch the sacred and the sacred must be protected from the influence of the profane and this is done with the existence of a number of interdictions. Such restrictions or taboos accord certain powers to the affected individuals or objects and places them at vantage points in the hierarchy of sacred and profane activities, may be at the top or bottom. Such tabooed individuals were feared, for they are thought to be fraught with transmissible powers which are dangerous. They are infectious and contagious and hence must be avoided. Any violation of taboo is bound to meet with punishment, meted out either by the taboo itself or by the divine power or through social sanction.

Indian society has never relinquished itself of its primitive characteristics and as such the positive and negative cults mentioned by Durkheim exist, with their distinctive features in the society. The notion of pollution is one aspect of the negative cult arising from the profane sphere which denies the affected individuals the right to confront the sacred. The Tamils in Malaysia, too, punctiously observe and obey the taboos relating to tīttu.

$T \overline{i t} t \underline{u}$ is a state of primary disability which separates one from the sacred, which is why when in a state of pollution the individual should not enter the temple or the prayer room, participate in auspicious ceremonies or apply the holy ash on the forehead. In other words, it amounts to a lack of fitness to communicate with the divine or sacred forces. Pollution disqualifies one from interaction with the sacred because it represents a concentration of the aspects of bodily existence which contradicts the sacred. When an individual is born, dies or menstruates this person is affected by change and instability in the form of individual embodiment over which he has no control. When there is no control, there is involvement of bodily flux and a vulnerability to evil spirits. ${ }^{10}$ Birth makes the mother weak who loses self-control and thus defenceless, while death as a traumatic event causes temporary emotional instability which also contributes to defencelessness against the forces of evil who might set in at such opportune moments. The per-

\footnotetext{
${ }^{9}$ E. Durkheim., The Elementary Forms of Religious Life., (New York, Collier Books, 1961), pp. 299-389.

${ }^{10}$ In her study entitled Pollution in Practice : Ritual, Structure and Change in Tamil Sri Lanka, Ph.D. Thesis, (Cornell University, Cornell, 1980), pp. 107-150, Kathleen Ryan also hypothesises on similar lines and draws attention to yoga, temple worship and maya (the intrinsic aspect of existence) to explain pollution. She argues that transcendence of flux, the limitations of human space and time, makes one eligible to interact with the sacred. On the other hand, another anthropologist, Ortner, studied pollution among the Sherpas (Buddhist group in Nepal) and represents a triangulation of three fundamental principles in Sherpa world view - the spiritual, the physical and the demonic. Pollution represents ascendency of the physical and/or demonic; purity an ascendency of spirituality. See S.B. Ortner, Sherpas through their rituals. (Cambridge, University Press, 1978) pp. 103-109.
} 
sons who lack control in the case of birth are the mother and child who are considered as polluted, while in the case of menstruation, it is the menstruating person. But in the event of death, all the immediate family members are affected by the pollution because it is they who are alive to the ordeal and thus lose selfcontrol temporarily. Losing self-control implicitly implies vulnerability to untoward influences.

Vulnerability or defencelessness appears to be an important feature of the notion of pollution. The lack of self-control caused by birth, menstruation and death makes the individual vulnerable to demons and spirits. The practice of valai kāppu, a ceremony where a pregnant woman in her seventh month of pregnancy undergoes a 'protection' ritual, the practice of carrying an iron key by a menstruating woman to ward off evil influences, ${ }^{11}$ the purification ceremonies after childbirth and death and the cleaning of the house, clothes and utensils after a funeral and isolation outside the house of a girl who menstruates for the first time all point towards the primary fear of the effects of pollution which brings in its wake susceptibility to the influence of ghosts and spirits called pēe, picacu and $\bar{a} v i$. If this argument of the fear of spirits and evil forces stands, then the purification ceremonies held after childbirth, after the first menstruation and after death can be termed a mitigated form of exorcism. It is the exorcism of the possible presence of ghosts and spirits. Culturally exorcism is considered as rites of purification. The 'tom-tom' beating during funerals which begins with the death and ends till the corpse is buried or cremated can be seen as a way to drive away the evil spirits through the loud beating of the drums. The period of pollution of sixteen or thirty days after birth, nine days after first menstruation and sixteen days after death after which a purification ceremony is held is the period allowed for the affected individual or individuals to recover their self-control so as to withstand the influence of evil forces. The period of $t \bar{t} t t u$ varies with caste and family customary practices and so does the additional observations and prohibitions imposed on the affected individuals.

In fact, the observance of taboos and restrictions, such as not being allowed to cook, play with babies, attend auspicious functions and go to temples, have possible relationships with the fear of vulnerability to evil spirits. As evil spirits symbolise impurity, inauspiciousness and uncleanliness, which is the antithesis of the qualities of the sacred, the Hindus could have extrapolated the concept to include these restrictions. Usually many of these restrictions have been less strictly observed depending on the circumstances, except that which involved the

\footnotetext{
${ }^{11}$ Even in Hindu mythology menstrual blood has been associated with evil. It has been portrayed as inauspicious and the source of a number of demons. The Mabäbbärata, for example, cites various examples of the origin of evil characters from the fertilization of menstrual blood. See W.D. O'Flaherty. Sexual Metaphors and Animal Symbols in Indian Mytbology. (Delhi, Motilal Banarsidass, 1981), pp. 33-35.
} 
sacred. The sacred represents purity while the evil spirits represent impurity and that is why when in a state of pollution, the divine is avoided. They do not communicate with the sacred until they have purified themselves either through the purification rites or through a wash or bath if the pollution is mild. Pollution is considered mild if the source is not death, birth and menstruation, in other words the source is acuttam not tittu.

So far it has been established that loss of self-control is the state of being which makes one vulnerable to evil influence, but what causes the loss of self-control in an individual is an important facet of my attempt to explain the notion of pollution. It may be an event like birth, death or menstruation but what do they signify in an individual? Such events are basically a change in the state of an individual or individuals which weakens the self-control, thus vulnerable to untoward influences. Mandelbaum mentions of a general apprehension among Indians of transition states, that is, from one physical being to another caused by one of such events like birth, death, menstruation and even cutting of hair. ${ }^{12}$ Consumption of food is also a source of change in an individual, both mentally and physically. That is why a man who has taken a bath is considered pure, but on consumption of food undergoes change and has attained a mild state of impurity, depending again on the type of food consumed. Even the transition of heavenly bodies as on the days of full moon and new moon, is believed to create a situation when supernatural powers were imminently present. The time of eclipse is regarded by Hindus as a time of great vulnerability during which special precautions are taken to ward off evil influences. Thus change in an individual from one state of being to another caused by sources of tittu and sometimes even acuttam ushers in a temporary loss of control or unsteadiness in oneself. By sources of acuttam it is meant alcohol, which reduces mental control and also meat which is believed to make the mind unsteady. Both contradict the sacred.

In the same line of thought we find that change does not occur only in an individual's state of being, it is also bound to occur in a group whereby the size of the group changes. An event like birth and death apparently brings a change in the size and nature of kin group, thus all close kins are assumed to have been affected by the pollution thus radiated. When a girl first menstruates it marks a change in her position in the kin group. She is marriageable and will soon leave the family. But it marks only a potential change in the size of the group, not an immediate change such as birth and death. As such, we find only some groups recognising first menstruation as a matter of group pollution and lesser importance is assigned to group pollution. Monthly menstruation is an individual pollution as it is a change in being only for the woman and not the group. Pollution thus becomes a

${ }^{12}$ D.G. Mandelbrum, op.cit., p. 204. 
group concern when the limits, form or size of the kin group changes, that is, when someone is born or dies. Pollution arising out of acuttam is also individual pollution which has no bearing on the group.

It is the writer's contention that the notion of pollution needs to be interpreted basically as a psychological phenomenon since the sources of $t \bar{t} t t+u$ affects the psychological disposition of the individual or individuals. The change in state, loss of self-control, feeling of vulnerability and fear are all descriptions of the psychological nature of individuals affected by events like birth, death or menstruation. The Hindus term it a state of pollution because of the fear that evil influences might be present. The denial of the privilege to communicate with the sacred when in a state of titțu can be understood as an extrapolation of the concept of purity because when in a state of pollution one is apparently impure. The sacred as a paragon of purity is the antithesis of whatever is impure, thus the disqualification of an individual to confront the divine.

\section{REFERENCES}

BOSE, D. The Problems of Indian Society. Bombay, Popular Prakashan, 1968.

DUMONT, L. Homo Hierarcbicus : the caste system and its implications. (Trans, by Mark Sainsbury). London, Weidenfeld and Nicolson, 1970.

DURKHEIM, E. The Elementary Forms of Religious Life, New York, Collier Books, 1961.

GHURYE, G.S. Caste and Race in India. Bombay, Popular Prakashan, 1959.

MANDELBAUM, D.G. Society in India: Continuity and Change. Vol, 1. Berkeley, University of California Press, 1970.

MANI, A. Changing Structure of Caste Among Singapore Hindus, M.Soc.Sc. Thesis, Department of Sociology, University of Singapore, Singapore, 1976.

ORTNER, S.B. Sherpas through their rituals. Cambridge, Cambridge University Press, 1978.

RYAN, K.S. Pollution in Practice : Ritual, Structure and Change in Tamil Sri Lanka. Ph.D. Thesis, Cornell University, Cornell, 1980.

SRINIVAS, M.N. Religion and Society among the Coorgs in South India. Oxford, Clarendon Press, 1952. 